\title{
An unusual cause of hip pain
}

\author{
Rizwan Rajak, Jeremi Camilleri \\ Rheumatology Department, University Hospital of Wales, Cardiff, UK
}

Correspondence to Dr Rizwan Rajak, rizrajak@yahoo.co.uk

\section{Summary}

The authors describe a case of bilateral transient regional osteoporosis of the hips occurring in a primigravida patient, which resolved spontaneously postpartum, leaving no residual damage. The authors review the existing literature regarding this disease.

\section{BACKGROUND}

This is an important case which bears on several specialities and can present to many different medical niches including general practice, general medicine, obstetrics, rheumatology and orthopaedics. More awareness and understanding of the condition, the difficulties in diagnosing it and the investigative and management strategies need to be better known to alert diagnosticians.

\section{CASE PRESENTATION}

A 32-year-old woman into her 23rd week of her first pregnancy described a 5 week history of progressive right hip pain on ambulation. The pain was felt mainly in the groin and buttock. Subsequently, she had been using crutches as weight-bearing became intolerable. She also reported milder symptoms in her left hip. There was no pain at rest. She had no other significant illnesses and was otherwise systemically well.

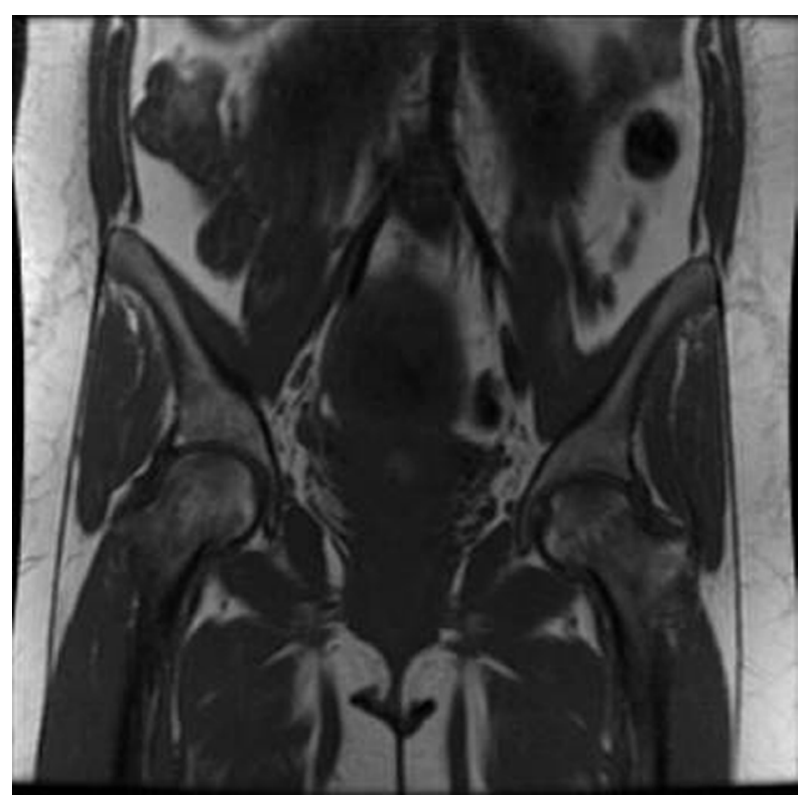

Figure 1 T1-weighted MRI, coronal view of pelvis showing decreased signal uptake within the femoral heads and necks bilaterally consistent with bone marrow oedema. The patient's pregnancy is in the early weeks of the third trimester.
Examination revealed no focal tenderness on palpation around the hip joints. There was moderate global restriction of movements in the right hip due to pain. Her left hip was fully mobile and tenderness was felt only on extremes of movement.

\section{INVESTIGATIONS}

Plain x-ray was contraindicated due to pregnancy. Laboratory tests including inflammatory markers were unremarkable. MRI of the pelvis showed decreased signal intensity on the T1-weighted images (figure 1) and increased signal intensity on the $\mathrm{T} 2$-weighted images (figure 2) characteristic of bilateral oedema in the femoral heads and necks with crescent sign present on the right femoral head (figures 3 and 4). There was no obvious structural loss to the femoral heads. These findings suggested a diagnosis of bilateral early avascular necrosis (AVN). She did not have any risk factors for AVN, such as corticosteroid use or excessive alcohol consumption, other than

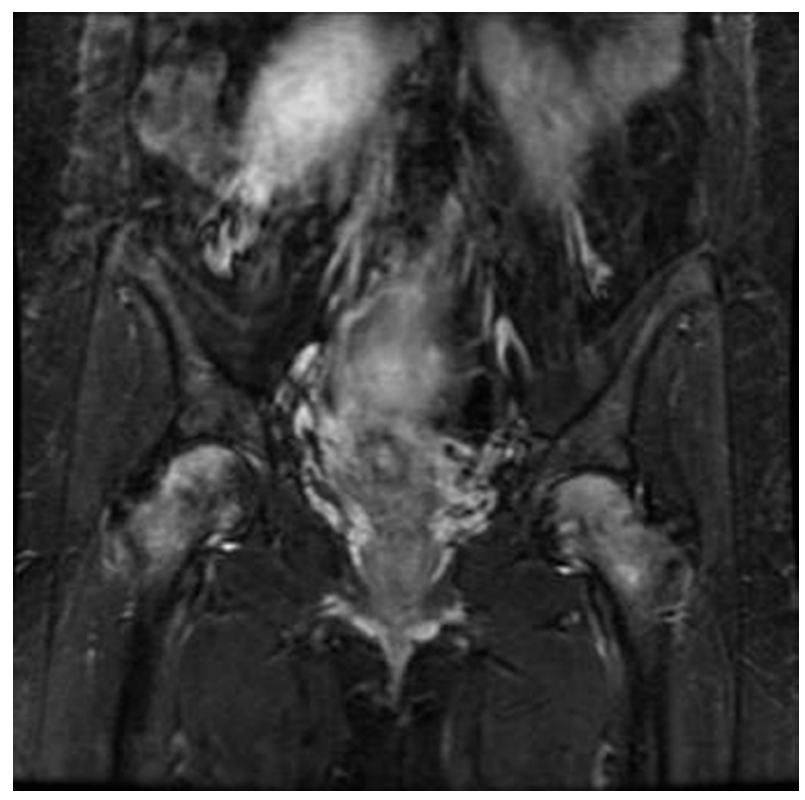

Figure 2 T2-weighted short-tau inversion recovery (STIR) MRI, coronal view of pelvis showing increased signal uptake within the femoral heads and necks bilaterally. 


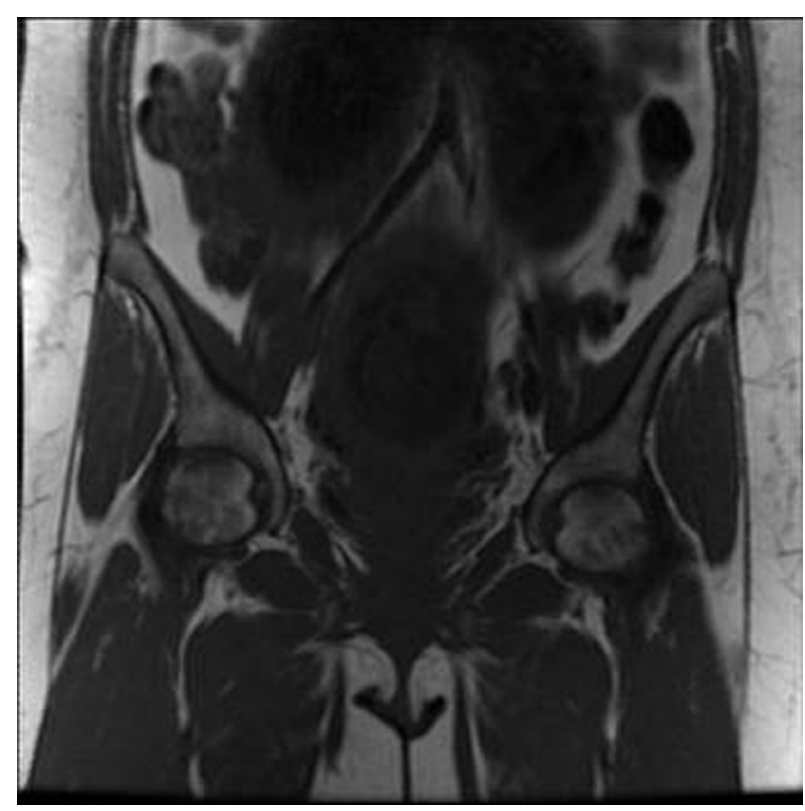

Figure 3 T1-weighted MRI, coronal view of pelvis (anterior to figure 1) showing crescent sign on the right femoral head. This is normally associated with avascular necrosis.

pregnancy. She was investigated for predisposing hypercoagulable conditions for AVN, of which, no abnormality was identified.

\section{TREATMENT}

The outcome for prognosis and recovery was indiscernible at this stage, however, we expected long-term sequelae from the osteonecrosis. Surgical intervention was not deemed appropriate and bisphosphonates were contraindicated due to the pregnancy. She was instructed to use basic analgesia for pain, avoid weight-bearing and encouraged to undertake low-impact exercises such as swimming until delivery. A plan was made to obtain postpartum imaging and consider treatment with pamidronate.

\section{OUTCOME AND FOLLOW-UP}

Her pregnancy resumed without complication and a caesarean section was performed at term. Surprisingly, her postpartum MRI (6 weeks later) revealed complete resolution of the oedema of the femoral heads and necks (figures 5 and 6). There was no evidence of subchondral collapse from the initial insult. The patient was now asymptomatic and able to resume independent weight-bearing.

The resolution without subchondral collapse of the femoral heads suggests that the original diagnosis was bilateral transient regional osteoporosis (TRO) of the hips.

\section{DISCUSSION}

TRO is a rare cause of hip pain that lacks any early effective diagnostic markers. It is not widely recognised and likely underdiagnosed. Though bilateral involvement is common (40\%), simultaneous involvement is rare and is almost exclusively seen in pregnant patients. ${ }^{1}$ The archetypal affected patient is either a pregnant woman in her third trimester or a middle-aged man. The typical clinical course of TRO is well-reported: in 12 cases of hip TRO

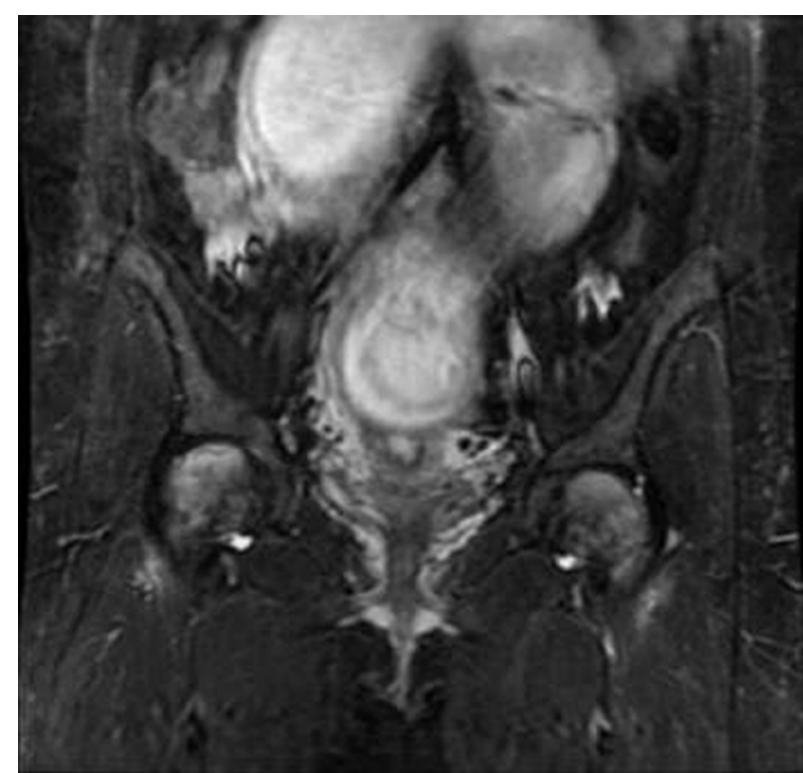

Figure 4 T2-weighted STIR MRI, coronal view of pelvis (anterior to figure 2) showing crescent sign on the right femoral head.

published in $2009^{2}$, all presented with hip pain with deterioration during walking, and x-ray and MRI radiography showed diffuse osteopenia and bone marrow oedema, respectively, in the femoral heads and necks. All patients improved on non-weight bearing regimens (three patients received bisphosphonate per os) with complete resolution of symptoms and radiology abnormalities between 6 and 9 months. TRO can occasionally be recurrent: one case describes a patient who developed bilateral hip TRO and subsequently experienced a relapse in the right hip 5 years later; the episodes presented similarly with identical radiological abnormalities resolving with conservative treatment within 5 months. ${ }^{3}$ Others skeletal areas affected by TRO in pregnant women - namely the lower limb areas such as the ankles, feet and knees - have common radiological changes and take a similar disease course. ${ }^{4}$

Historically, TRO has been thought of as variants of regional migratory osteoporosis ${ }^{5}(\mathrm{RMO})$ and non-traumatic variety of reflex sympathetic dystrophy ${ }^{6}$ (RSD), however key differences - namely the migratory nature and predilection for lower limb regions in $\mathrm{RMO}$ and the cutaneous trophic features and disease chronicity in RSD differentiate TRO as a distinct clinical diagnosis.

The association with pregnancy seems clear; in one case, a pregnant patient in her first trimester developed TRO which resolved following a therapeutic abortion. ${ }^{7}$ Recurrence of TRO in multiple pregnancies in the same patient has also been reported. ${ }^{8}$ Rather than the hypercoagulable state, one study suggests that the increased demand on maternal skeletal stores which is met by increased maternal bone resorption and formation, may predispose the development of TRO. 9

In the early stages of the disease, TRO is clinically and radiologically indistinguishable from AVN. While the cause of TRO is unknown, AVN is considered to result from ischemic injury to bone and marrow tissues. It has been suggested that TRO may represent the early reversible phase of AVN. ${ }^{10}$ Perfusion studies have demonstrated asymmetry in the perfusion and size of nutrient arteries of 


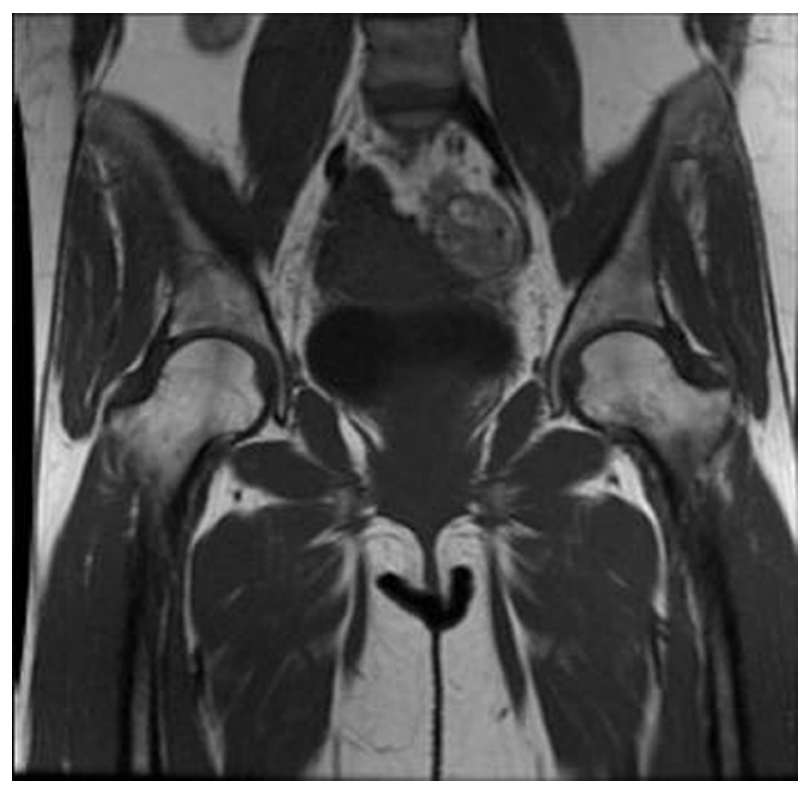

Figure 5 T1-weighted MRI, coronal view of pelvis taken 6 -weeks postpartum. It shows a complete return of signal intensity in the femoral heads and necks and therefore, resolution of the bone marrow oedema, with no evidence of subchondral collapse.

the affected hip in patients with unilateral TRO suggesting that a vasomotor response, leading to bone medullary hypertension and subsequently ischaemia, may be implicated in its inception. ${ }^{11}$ One characteristic that differentiates the conditions is the presence of subchondral collapse of the femoral heads, suggestive of AVN. However, this is may be a late finding and be missed depending on the timing of imaging. One group ${ }^{10}$ looked at bone biopsies on three patients diagnosed with TRO based on clinical and radiological ( $\mathrm{x}$-rays, bone scintigram and $\mathrm{MRI}$ ) assessments. The most unifying feature was focal areas of disconnected bone trabeculae covered by osteoid seams with surrounding bone marrow tissue oedema and vascular congestion. No osteonecrosis was seen. All the subjects improved spontaneously with no follow-up evidence of osteonecrosis. Though the study was small, they concluded that TRO and AVN are separate entities.

Radiological distinction between TRO and AVN is potentially achievable through bone scintigraphs (although in pregnancy it would be contraindicated). In TRO, the typical finding is of diffuse, homogenous and intense uptake of isotope extending from the femoral heads to the intertrochanteric line whereas in AVN the isotope uptake is heterogenous and less intense and there may be a focal area of photopenia in the anterosuperior region. ${ }^{12}$

Malizos' radiological group ${ }^{13}$ evaluated 42 patients who were diagnosed with TRO after excluding AVN, comparing closely their unifying features with attention paid to subchondral changes and the pattern of bone marrow oedema (BMO) on x-rays and MRI. $87 \%$ of patients had osteopenia and the most frequent $\mathrm{BMO}$ pattern was extension to the femoral head and neck. Only two subjects had femoral head changes but no patient had subchondral collapse or change in sphericity on follow-up. This combination of osteopenia and $\mathrm{BMO}$ without subchondral

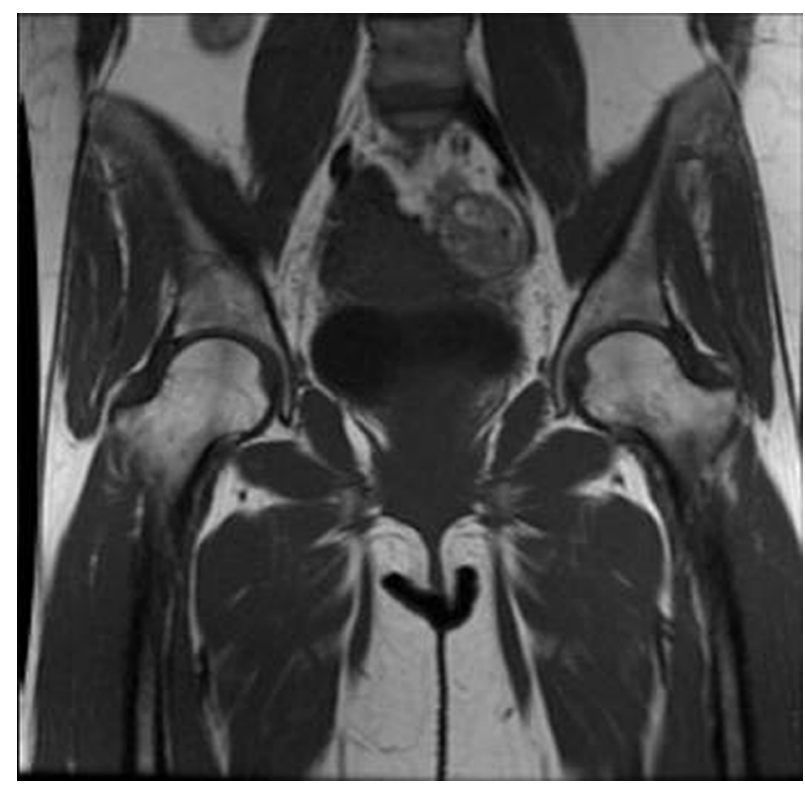

Figure 6 T2-weighted STIR MRI, coronal view of pelvis, 6 -weeks postpartum. It shows marked reduction in signal intensity of the femoral heads and necks without subchondral collapse.

disease mirrors the clinical course of other commentaries of TRO. ${ }^{1-4} 914$

The majority of reported cases of TRO are self-limiting. One report ${ }^{15}$ has proposed the effectiveness of using intravenous pamidronate in achieving prompt resolution and prevention of relapses in TRO; clinical recovery occurred by 1 month and MRI normality was seen within 3 months. However, delineating the effect of treatment and the natural course of the disease is difficult. Certainly, surgical intervention should be avoided particularly in the face of normal laboratory tests, negative cultures and diffuse bone marrow oedema on MRI. ${ }^{14}$ The overall consensus is that TRO is best managed with analgesia, rehabilitation and protected weight-bearing, which is essential to avoid stress fractures.

Only by closely monitoring these patients with serial clinical assessments and imaging, can the diagnosis be ascertained and this is often, as in our case, only achieved retrospectively. More knowledge is necessary to characterise the disease from AVN, since TRO is typically self-limiting while AVN progresses eventually requiring surgical intervention.

\section{Learning points}

- Radiological diagnoses of AVN in pregnancy should always alert the diagnosis of TRO which is reversible and self-limiting.

- TRO still lacks early effective diagnostic markers that distinguish it from AVN, the latter associated with significant morbidity.

- Diagnosis of TRO may only be achieved retrospectively as the natural course of the disease ensues and, therefore, invasive surgical treatment should be postponed unless significant stress fractures occur. 


\section{BMJ Case Reports}

\section{Competing interests None.}

Patient consent Obtained.

\section{REFERENCES}

1. Lakhanpal S, Ginsburg WW, Luthra HS, et al. Transient regional osteoporosis. A study of 56 cases and review of the literature. Ann Intern Med 1987;106:444-50.

2. Paraschou S, Makiev G, Anastasopoulos H, et al. Transient osteoporosis of the hip-A report of 12 cases. EEXOT 2009;60:186-90.

3. Ikemura S, Yamamoto T, Jingushi S, et al. Recurrent transient osteoporosis of the hip. Euro J Radiol Extra 2008;66:65-9.

4. Daniel RS, Farrar EK, Norton HR, et al. Bilateral transient osteoporosis of the talus in pregnancy. Osteoporos Int 2009;20:1973-5.

5. Kaplan SS, Stegman CJ. Transient osteoporosis of the hip. A case report and review of the literature. J Bone Joint Surg Am 1985;67:490-3.

6. Lequesne M. Transient osteoporosis of the hip. A nontraumatic variety of Südeck's atrophy. Ann Rheum Dis 1968;27:463-71.

7. Chigira M, Watanabe H, Udagawa E. Transient osteoporosis of the hip in the first trimester of pregnancy. A case report and review of Japanese literature. Arch Orthop Trauma Surg 1988;107:178-80.
8. Shifrin LZ, Reis ND, Zinman H, et al. Idiopathic transient osteoporosis of the hip. J Bone Joint Surg Br 1987:69:769-73.

9. Boissonnault WG, Boissonnault JS. Transient osteoporosis of the hip associated with pregnancy. J Orthop Sports Phys Ther 2001;31:359-65: discussion 366-7.

10. Yamamoto T, Kubo T, Hirasawa Y, et al. A clinicopathologic study of transient osteoporosis of the hip. Skeletal Radiol 1999;28:621-7.

11. Koo KH, Ahn IO, Song HR, et al. Increased perfusion of the femoral head in transient bone marrow edema syndrome. Clin Orthop Relat Res 2002:402:171-5.

12. Balakrishnan A, Schemitsch $E H$, Pearce $D$, et al. Distinguishing transient osteoporosis of the hip from avascular necrosis. Can J Surg 2003;46:187-92.

13. Malizos KN, Zibis AH, Dailiana Z, et al. MR imaging findings in transient osteoporosis of the hip. Eur J Radiol 2004;50:238-44.

14. Komatsu T, Kadoya Y, Minoda Y, et al. Transient osteoporosis of the femoral condyle: a case report. Knee 2002;9:241-3.

15. Varenna M, Zucchi F, Binelli L, et al. Intravenous pamidronate in the treatment of transient osteoporosis of the hip. Bone 2002;31:96-101.

This pdf has been created automatically from the final edited text and images.

Copyright 2011 BMJ Publishing Group. All rights reserved. For permission to reuse any of this content visit

http://group.bmj.com/group/rights-licensing/permissions.

BMJ Case Report Fellows may re-use this article for personal use and teaching without any further permission.

Please cite this article as follows (you will need to access the article online to obtain the date of publication).

Rajak R, Camilleri J. An unusual cause of hip pain. BMJ Case Reports 2011;10.1136/bcr.07.2011.4456, date of publication

Become a Fellow of BMJ Case Reports today and you can:

- Submit as many cases as you like

- Enjoy fast sympathetic peer review and rapid publication of accepted articles

- Access all the published articles

- Re-use any of the published material for personal use and teaching without further permission

For information on Institutional Fellowships contact consortiasales@bmjgroup.com

Visit casereports.bmi.com for more articles like this and to become a Fellow 